\title{
The Fine Structure of Mesosomes and Plasma Membrane in Streptomyces coelicolor
}

\author{
By H. WILDERMUTH* \\ John Innes Institute, Norwich, NOR $70 F$ \\ (Accepted for publication 23 June $197 \mathrm{I}$ )
}

\begin{abstract}
SUMMARY
The fine structure of the plasma membrane and the mesosomes of Streptomyces coelicolor was studied by means of serial sections of aerial mycelium fixed in glutaraldehyde and osmium tetroxide, by negative staining of intact cells and cell fragments, and by freeze-etching. The plasma membrane as seen in freezeetch preparations showed the typical features of bacterial plasma membranes: it was densely covered with small particles when viewed from the convex side. In serial sections it was possible to follow corresponding 'unit membranes', suggesting the existence of spaces bounded by extensive lamellae. Negative staining revealed stacks of tubes and also spaces confined by lamellae. Vesicles were only rarely encountered. In freeze-etch preparations the mesosomes appeared mostly as clusters of vesicles, but lamellar and tubular regions were also found. It is suggested that 'the mesosome' with a uniform anatomy does not exist but that lamellae, tubes and vesicles arise from each other.
\end{abstract}

\section{INTRODUCTION}

In Streptomyces mesosomes were first described by Glauert \& Hopwood (1959) in Streptomyces coelicolor, by Stuart in S. noursei (1959) and by Moore \& Chapman (1959) in an unidentified streptomycete. Later, extensive intracytoplasmic membranes were also found in S. cinnamonensis (Chen, I964), S. viridochromogenes (Rancourt \& Lechevalier, 1964) and $S$. venezuelae (Bradley \& Ritzi, I968). All these publications dealt with non-serial sections of mesosomes fixed in osmium tetroxide. This technique alone does not provide enough information for the reconstruction of the three-dimensional structure of these complicated organelles, so the new techniques in electron microscopy which have been developed since the work of Glauert \& Hopwood (1959, 1960) made a fresh study desirable. In order to obtain new information on the structure of mesosomes they were examined by means of different methods: serial sectioning of double-fixed material, negative staining of intact cells and cell fragments and freeze-etching.

The mesosomes appear in sections to consist of clusters of 'unit membranes' which are often continuous with the plasma membrane. Therefore the latter was also included in this study for comparison, especially since it has been shown in bacilli by freeze-etching that there are clear structural differences between mesosomal and plasma membranes (Nanninga, 1968; Remsen, 1968; Holt \& Leadbetter, 1969).

This report is one of a series of papers dealing with the morphological characterization of Streptomyces coelicolor strain A3(2) (Wildermuth, 1970b; Wildermuth \& Hopwood, 1970). These investigations form the basis for a study on the genetic control of the sporulation process (Hopwood, Wildermuth \& Palmer 1970).

\footnotetext{
* Present address: Zoologisches Institut der Universität, Künstlergasse 16, Zurich, Switzerland.
} 


\section{METHODS}

Organism and growth conditions. Streptomyces coelicolor strain A3(2) (S. violaceoruber according to Kutzner \& Waksman (1959)), obtained from Professor D. A. Hopwood, was grown on chemically defined agar medium ('minimal medium'; Hopwood, 1967) at $30^{\circ}$. For an experiment in which the hyphal wall was digested with lysozyme, substrate mycelium was grown from a spore suspension. This was inoculated in liquid minimal medium enriched with casein hydrolysate (Difco Casamino acids, $0.6 \%$ ) and incubated for $\mathrm{I} 6 \mathrm{~h}$. at $30^{\circ}$ on a New Brunswick gyrotary shaker.

Chemical fixation and sectioning. Single colonies containing mature spores were fixed with glutaraldehyde and osmium tetroxide as previously described (Wildermuth $1970 \mathrm{~b}$ ) and embedded in Araldite. Thin sections were cut with glass knives on an LKB Ultrotome III microtome and picked up on carbon coated grids.

Negative staining of intact cells. Whole mounts of aerial hyphae and spores were obtained by touching the top of vigorously sporulating colonies with a carbon-coated grid and the impressions negatively stained with $2 \%(\mathrm{w} / \mathrm{v})$ aqueous ammonium molybdate or $\mathrm{I} \%(\mathrm{w} / \mathrm{v})$ potassium phosphotungstate adjusted to $\mathrm{pH}_{7}$ (Wildermuth, 1970a, $b$ ).

Negative staining of isolated membrane fragments. Aerial hyphae and spores from mass cultures were suspended in ice-cooled distilled water, centrifuged at $4300 \mathrm{~g}$. The pellet was then suspended in a small volume of water, sonicated with ultrasound from a Mullard L364 ultrasonic generator for $20 \mathrm{~min}$. in an ice-cooled water bath, shaken in a Mickle cell disintegrator (glass beads size I6) at $4^{\circ}$ for Io min. and afterwards centrifuged at $9000 \mathrm{~g}$ for Io min. in a Spinco model L ultracentrifuge. The supernatant was again centrifuged at $58,000 \mathrm{~g}$ for $45 \mathrm{~min}$. and the residue negatively stained with $\mathrm{I} \%(\mathrm{w} / \mathrm{v})$ potassium phosphotungstate at $\mathrm{pH} 7$ (Brenner \& Horne, 1959).

Evagination of mesosomes and protoplast formation. The young mycelium in liquid medium was separated on a bench centrifuge at $8700 \mathrm{~g}$ for $3 \mathrm{~min}$., washed twice in $0.1 \mathrm{M}$-tris- $\mathrm{HCl}$ containing $40 \mathrm{~mm}-\mathrm{MgCl}_{2}$ and sucrose added as described by Ellar \& Freer (1969). After the eversion of the mesosomes the suspension was made I $M$ with respect to sucrose and the cell walls of the organism were digested by adding lysozyme (I $\mathrm{mg} . / \mathrm{ml}$.) in a shaking water bath at $37^{\circ}$. Samples for examination in the electron microscope were taken after 30,60 and I 20 min., centrifuged, washed in the staining solution and negatively stained with $\mathrm{I} \%(\mathrm{w} / \mathrm{v})$ potassium phosphotungstate.

Freeze-etching. Aerial mycelium was collected from sporulating mass cultures grown in plastic dishes, suspended in water, centrifuged and the pellet frozen-etched according to the method described by Moor (1964).

Electron microscopy. The specimens were examined in a Siemens Elmiskop Ia electron microscope at an accelerating voltage of $80 \mathrm{kV}$. Photographs were taken at instrumental magnifications from 8000 to 30,000 .

\section{RESULTS}

Plasma membrane. Freeze-etchings of the plasma membrane are shown in Fig. I and 3. When viewed from their convex sides the membranes were densely covered with particles of approximately 4 to $8 \mathrm{~nm}$. in diameter. On the other hand, when the membranes exhibited their concave side the particles were sparsely distributed. On the convex side short strands with about the same diameter as the round particles were detected (Fig. I). It is not certain whether the strands correspond to the connections between the cell wall and the plasma membrane as seen in other bacteria (Holt \& Leadbetter, 1969). 

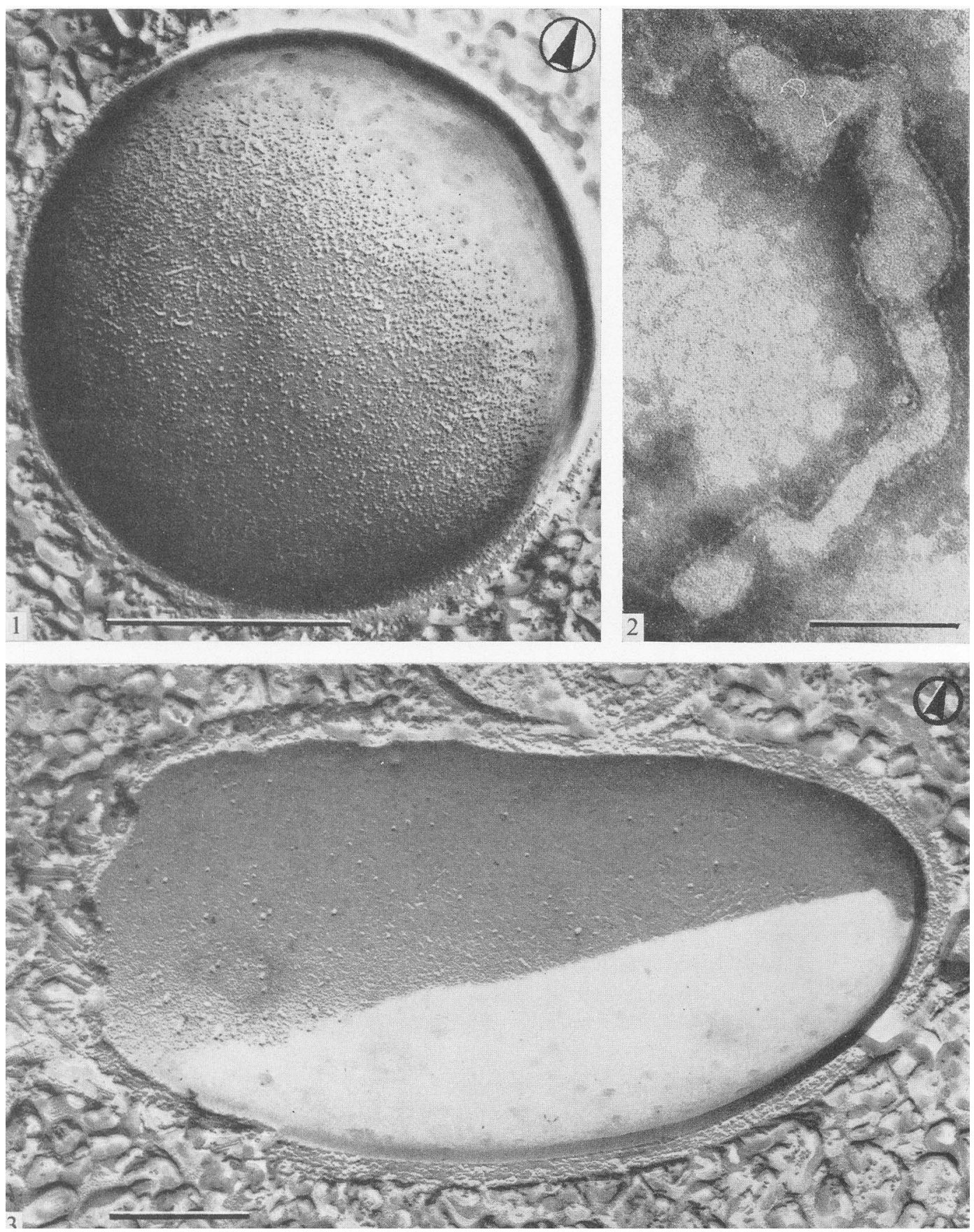

Fig. I. Freeze-fractured plasma membrane of a spore showing the convex side. The encircled arrow indicates the direction of shadow. Bar represents $0.5 \mu \mathrm{m}$.

Fig. 2. Negative staining of an isolated membrane fragment from a mechanically disrupted cell. Note the irregular particles on the surface of the fragment. Bar represents $0.1 \mu \mathrm{m}$.

Fig. 3. Freeze-fractured plasma membrane showing the concave side. Bar represents $0.25 \mu \mathrm{m}$. 

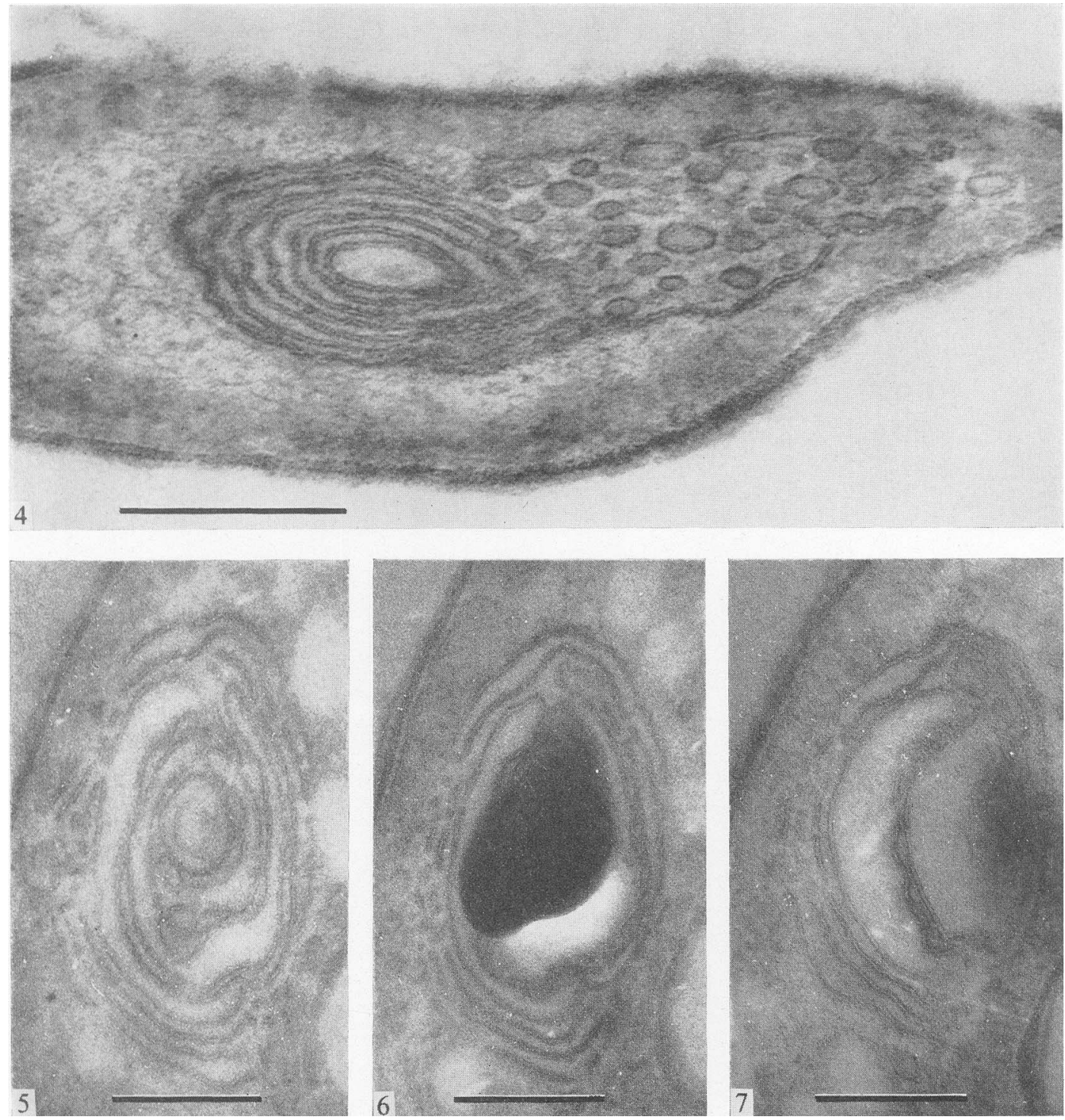

Fig. 4. Section through a large mesosome consisting of concentric lines, circles and ellipses in an aerial hypha. Bar represents $0.2 \mu \mathrm{m}$.

Fig. 5 to 7 . Serial sections through the same mesosome in an aerial hypha. Corresponding structures can be seen on each micrograph. The significance of the dense body in Fig. 6 is not known. Bar represents $0 \cdot 2 \mu \mathrm{m}$. 

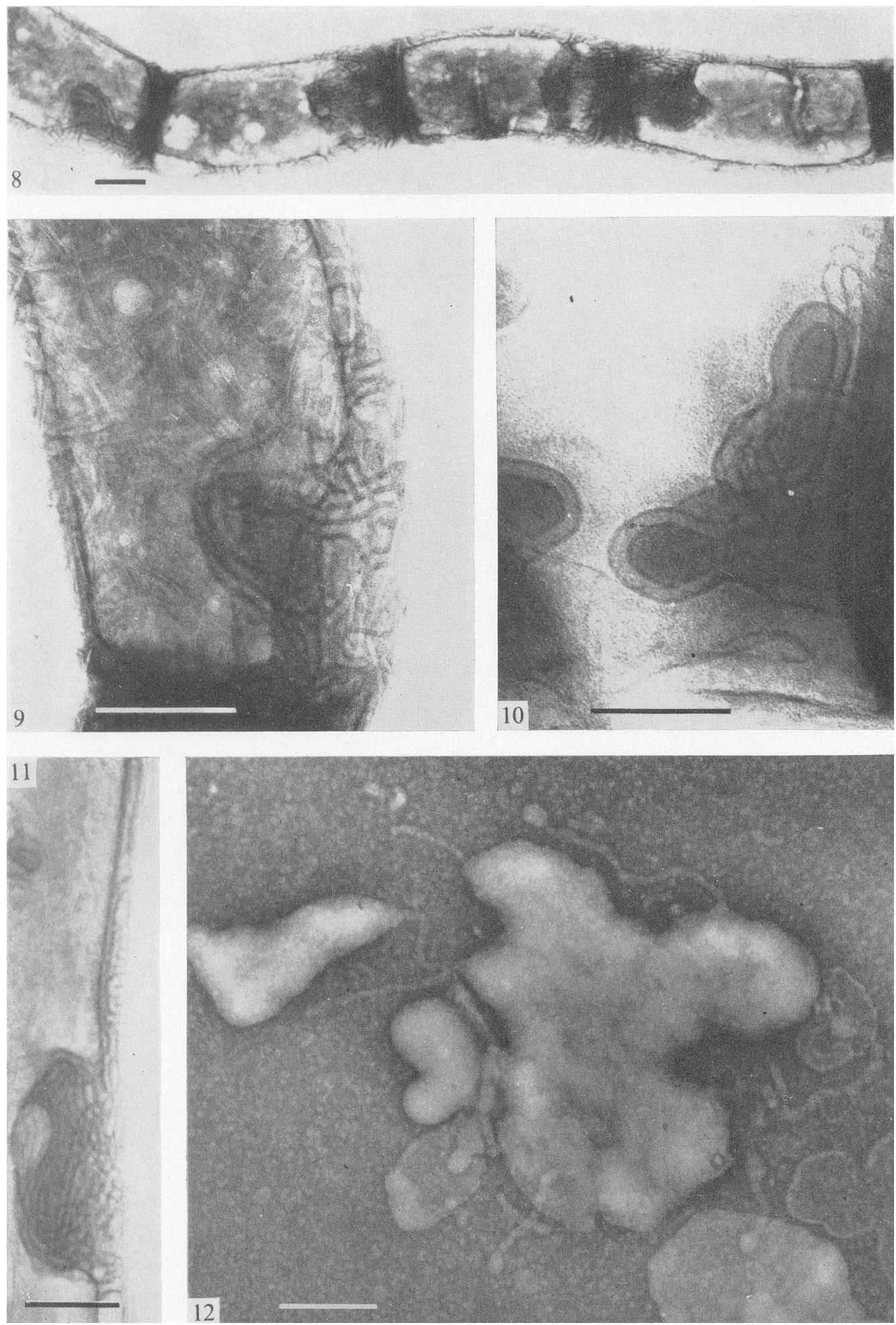

Fig. 8 to I I. Negatively stained preparations of mesosomes in intact cells. Fig. 8 shows a chain of young spores. In Fig. 9 and Io the mesosomal structures are seen as dense double lines separated by a transparent zone. The mesosome in Fig. II was partly extruded in the periplasmic space. Bar represents $0.25 \mu \mathrm{m}$.

Fig. I2. Negative staining of aerial mycelium treated with hypertonic solution and lysozyme. Note the membrane fragments and the tube-like structures. Bar represents $0.25 \mu \mathrm{m}$. 

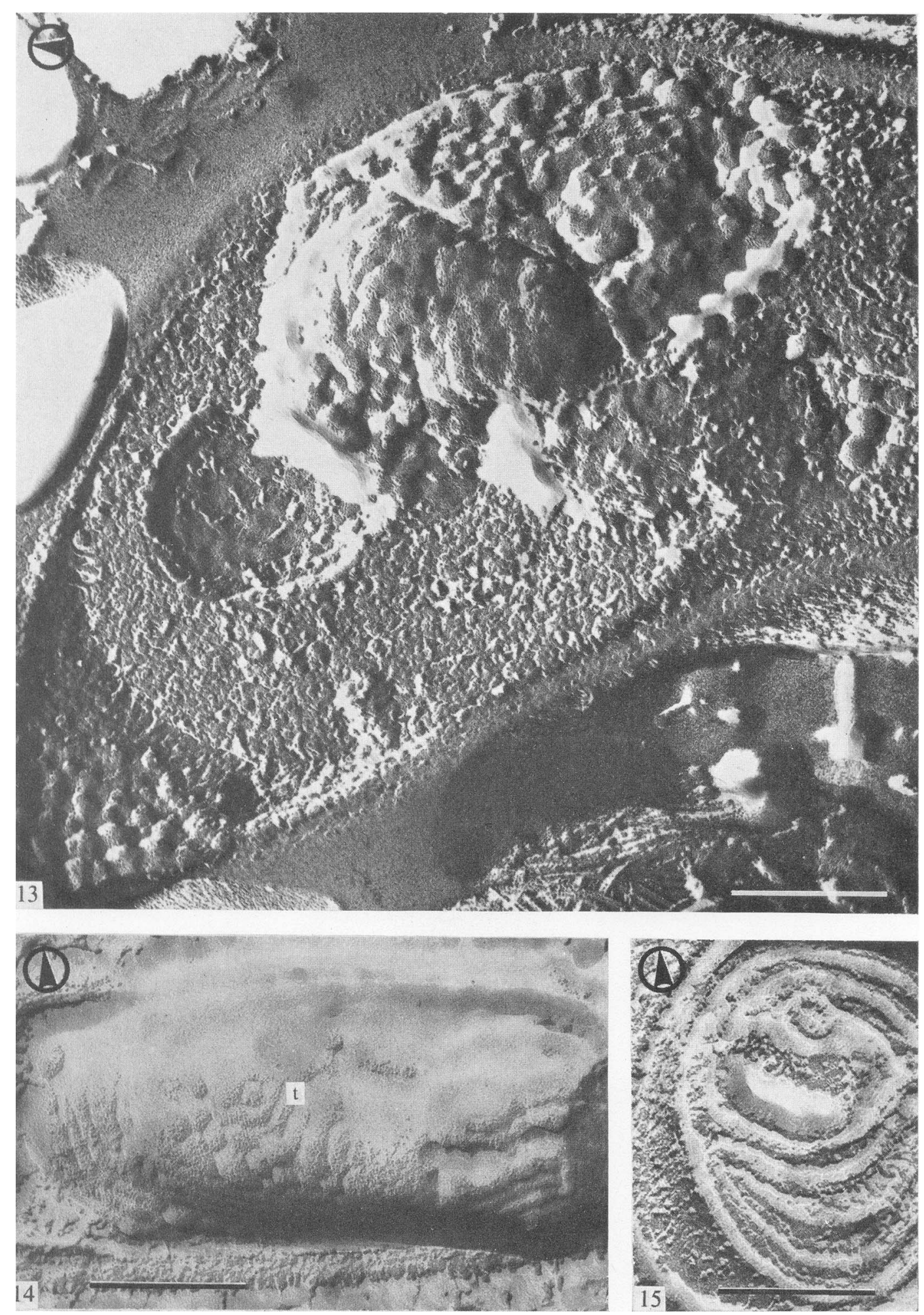
Fragments of membrane material were abundant in the final fraction of differentially centrifuged hyphae and spores which were previously disrupted (Fig. 2). The surface was occupied with small particles.

Mesosomes. In thin sections of aerial hyphae the mesosomes appeared mostly as mixtures of circles, ellipses and concentric lines (Fig. 4) consisting of triple-layered membranes ('unit membranes'). However, it was difficult to judge from sections whether the circles and ellipses represented cross sections of vesicles or convoluted and branched tubes. Groups of concentric lines could either correspond to longitudinally sectioned tubes or to compartments confined by lamellae. In serial sections it was possible to follow corresponding lines within mesosomes (Fig. 5 to 7 ). From this result it is concluded that the lines correspond to lamellae. In the example shown in Fig. 5 to 7 the membranes extend at least 300 to $400 \mathrm{~nm}$. perpendicular to the plane of the sections. It should be noted that this evidence for lamellae in mesosomes does not exclude the existence of tubes.

In negatively stained intact hyphae and spores electron-dense bodies which are interpreted as mesosomes were often observed. The frequency of these organelles per cell varied. In some cells they were very abundant while they were completely absent in others. The membranous bodies consisted mainly of groups of curved lines sometimes running parallel and it is thought that they represent tubes or pockets confined by membranes (Fig. 8 to II). A number of mesosomes encountered were evaginated in the periplasmic space (Fig. II). Occasionally they appeared as clusters of circles. The mesosomal spaces were confined by dense and mostly blurred lines, but occasionally they appeared as sharp double lines separated by a transparent zone (Fig. 9, I0). The dimensions of the double lines correspond approximately to those of 'unit membranes' as seen in thin sections of chemically fixed material.

Additional information was obtained from evaginated mesosomes of protoplasts. Although difficulties were encountered in obtaining protoplasts, in some instances tube-like appendages were clearly seen on the cell surface and it is believed that they represented parts of expelled mesosomes (Fig. I2). The surface of the membranous structures appeared smooth.

In the cytoplasm of frozen-etched cells there appeared conspicuous bodies which were considered to represent mesosomes (Fig. I 3 to I8). They consisted mostly of clusters of vesicles with a diameter of approximately $50 \mathrm{~nm}$. The vesicles were round, or, when occurring in dense clusters, hexagonally shaped. They were mostly seen from the outside (as convex structures) but occasionally concave views were also observed (Fig. I3). Fig. I4 shows a large mesosome which might consist of tubes or lamellae. On one side parallel lines are visible and on the top there are indications of convoluted tubes which end in vesicles. Crossfractured lamellae and vesicles are seen in Fig. I7. In this specimen the mesosome appears to be made of a number of superimposed membranes leaving vesicular spaces between them. Another cross-fracture of a group of intracytoplasmic membranes is seen in Fig. I5. As in single sections of chemically fixed material it cannot be decided whether they correspond to tubes or lamellae.

Fig. 18 is thought to represent a mesosomal envelope (note that it is a depression). It

Fig. 13 to 15 . Freeze-etch preparations of mesosomes in aerial hyphae. Fig. I3 shows a large mesosome mainly consisting of vesicles. Tubes $(t)$ ending in vesicles are seen in Fig. 14. The parallel lines running along the side of the mesosome may indicate the presence of stacks of tubes or of lamellae. A cross-fractured mesosome consisting of tubes or spaces bounded by lamellae is seen in Fig. 15. Bar represents $0.2 \mu \mathrm{m}$. Encircled arrows indicate the shadowing direction. 
shows vesicular protrusions and is sparsely dotted with particles. An unusual structure is seen in Fig. 16 in which the surface of a group of vesicles is continuous with a flat area exhibiting a crystal-like pattern.

Certain hyphae which are thought to be ageing cells were often filled with large round bodies (Fig. 19). In spite of their stratified appearance they are not made of membranes and there is hardly any connection with mesosomes. Presumably they correspond to the osmiophilic bodies or to the 'vacuoles' observed in sections of disintegrating hyphae (Wildermuth, $1970 b$ ).
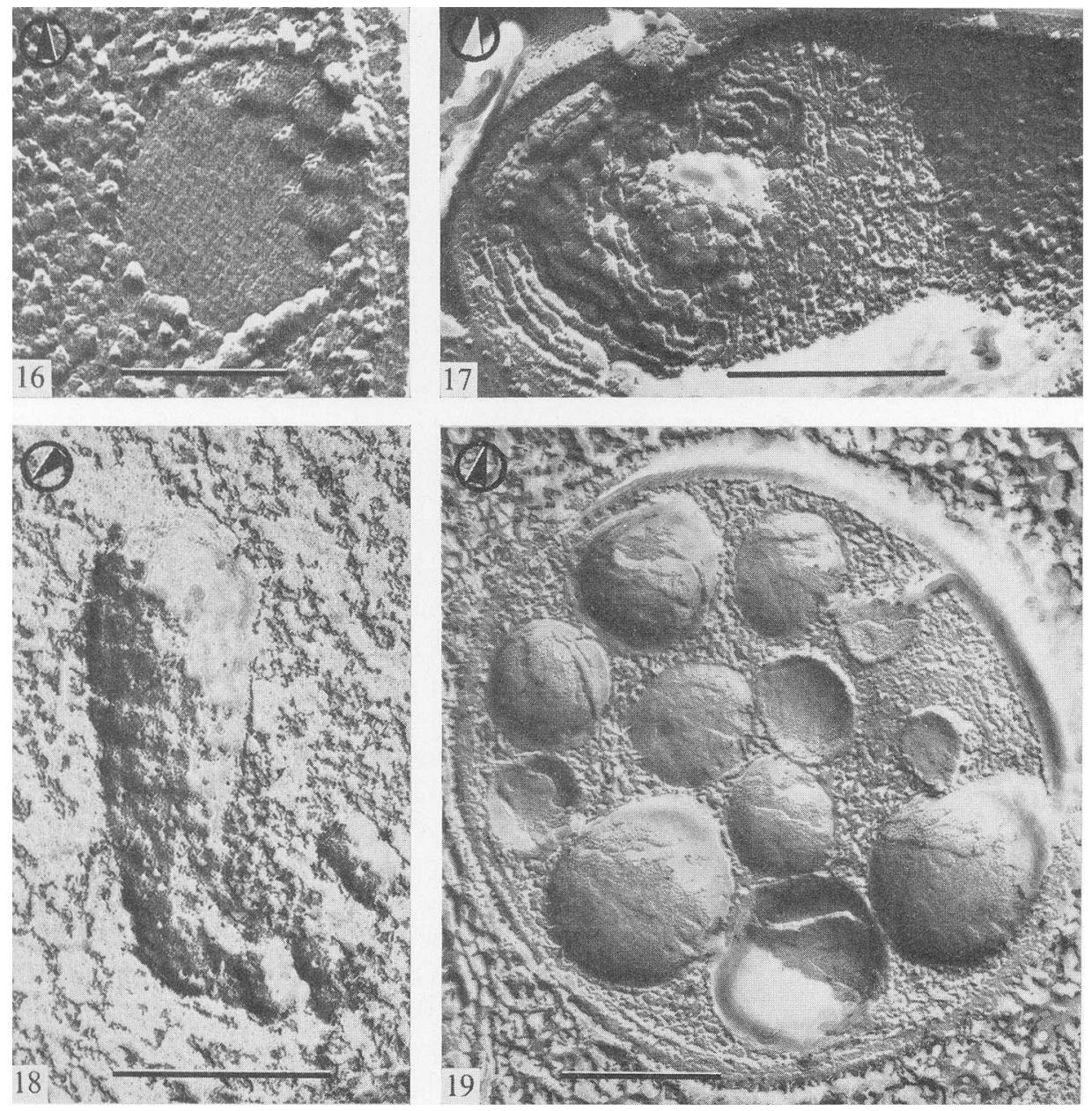

Fig. 16 to I8. Freeze-etch preparations of mesosomes. Fig. I6 shows an unusual crystal like pattern on an area which is in continuity with mesosomal vesicles; Fig. 17: mesosome with partly crossfractured lamellae. Fig. I 8 is thought to represent a mesosomal envelope which is sparsely dotted with particles. Bar represents $0.25 \mu \mathrm{m}$.

Fig. 19. Cross-fractured hypha which is filled with large round bodies. It is believed that the round bodies arise in disintegrating cells. There is probably no connection between these structures and the mesosomes. Bar represents $0.25 \mu \mathrm{m}$. Encircled arrows indicate the shadowing direction. 


\section{DISCUSSION}

Plasma membrane. In freeze-etch preparations the plasma membrane exhibited two different aspects of fine structure according to whether it was viewed from the convex or concave side. Mühlethaler, Moor \& Szarkowski (1965) suggested for chloroplast membranes that the difference was due to two fracturing faces following along the inner and outer surface of the membrane. In contrast Branton (I966) proposed a single fracture plane running through the interior of the membrane. This view was recently experimentally confirmed by Wehrli, Mühlethaler \& Moor (I970), who designed a method for double replication of corresponding membrane regions. According to their results with chloroplast thylakoids, the convex side of the bacterial plasma membrane is now interpreted as the 'inner fracture face' and no longer as the outside of the membrane. The 'outer fracture face', on the other hand, would now correspond to the former inner side of the plasma membrane.

The surface of isolated membrane fragments was occupied with very small particles of irregular size and appearance. They are smaller than those described in the plasma membrane of Bacillus stearothermophilus (Abram, 1965).

Mesosomes. The mesosomes of Streptomyces as seen in thin sections are structurally similar to those in other Gram-positive bacteria. The mesosomal components were always seen as triple layers ('unit membranes') and did not consist of compound membranes formed by the union of two 'unit membranes' as found in the myxobacterium Chondrococcus columnaris (Pate \& Ordal, 1967). Highton (1969) stated that the circular and oval components of the mesosomes in Bacillus licheniformis were bounded only by a single line. However, it is difficult to judge on the basis of his published micrographs whether the electron-dense line is single or double. In streptomyces the circles undoubtedly consist of 'unit membranes' and the same holds true for $C$. columnaris (Pate \& Ordal, I967).

Although the mesosomes of Streptomyces coelicolor could be followed in serial sections there are still some doubts with respect to their three-dimensional structure. This is especially true for the circles and ovals which might represent cross-sections through vesicles or tubes. Ryter (I968) suggested that the mesosomes in Bacillus subtilis consist only of vesicles and that lamellae are fixation artifacts. However, this does not appear to be true for streptomyces since concentric lines ('membranes') are still found in double-fixed cells. Ganboulan \& Leduc (1967) obtained similar results from double-fixed cells of $B$. subtilis. Furthermore, in this study a group of concentric lines in a mesosome could be followed in a series of adjacent sections. Corresponding observations were made by Highton (1970) in B. licheniformis. Those lines are considered to correspond to superimposed lamellae separated by narrow spaces. In addition lamellae were directly demonstrated in cross-fractured mesosomes of frozen-etched cells.

The curved lines of the cross-fractured mesosome shown in Fig. I 5 may correspond to the lines seen in sections. Remsen (1968) interpreted such structures as 'lamellated mesosomes' while Nanninga (I968) described similar cross-fractures as tubes.

Although lamellae certainly exist in mesosomes it is not excluded that tubes may also occur. In fact, short tubes ending in vesicles were demonstrated in freeze-etchings. Furthermore, the electron-dense parallel lines seen in negative stainings of intact cells may also be interpreted as tubes. However, it is conceivable that these are all transitions from tubes with circular profiles to larger spaces bounded by lamellae. Tube-like structures were furthermore observed in hyphae which were treated with hypertonic solutions of lysozyme. The negatively stained structures were similar to those obtained from corresponding experiments in Listeria 
monocytogenes (Ghosh \& Murray, 1969) and from Mycobacterium smegmatis (Cesari, Rieber \& Imaeda, 1969).

Highton (1969), in contrast to Ryter \& Landman (1964), considered 'vesicles' seen in sections of chemically fixed Bacillus licheniformis as artifacts, formed by breakdown of membranes. This possibility cannot be excluded, especially since the frequency of the vesicles could be experimentally varied by different treatments prior to fixation. On the other hand vesicles were clearly demonstrated in frozen-etched cells of various Bacillus species (Nanninga, I968; Remsen, 1968; Holt \& Leadbetter, 1969) and during this study in Streptomyces coelicolor. The vesicles occur singly, in small clusters, or in large aggregates. Presumably they communicate when occurring in groups.

In spite of the numerous publications on the fine structure of mesosomes there are still some uncertainties with regard to their three-dimensional structure. The morphological variation of these organelles as seen in the electron microscope might suggest that the mesosomes are of dynamic anatomy. Since their appearance varies within the same strain with respect to their shape, size, architecture, number per cell and topographical situation their structure may be continuously altered. Thus lamellae, tubes and vesicles could arise from each other as in the Golgi apparatus of eukaryotic cells where vesicles are persistently formed at the end of tubules.

It is a pleasure to thank Professor D. A. Hopwood for his critical reading of the manuscript. Thanks are due also to E. Wehrli, Department of General Botany, Swiss Federal Institute of Technology, Zurich, who kindly made the freeze-etchings.

\section{REFERENCES}

ABRAM, D. (1965). Electron microscope observations on intact cells, protoplasts, and the cytoplasmic membrane of Bacillus stearothermophilus. Journal of Bacteriology 89, 855-873.

Bradley, S. G. \& RitzI, D. (I968). Composition and ultrastructure of Streptomyces venezuelae. Journal of Bacteriology 95, 2358-2364.

Branton, D. (1966). Fracture faces of frozen membranes. Proceedings of the National Academy of Sciences of the United States of America 55, 1048-1056.

Brenner, S. \& Horne, R. W. (I959). A negative staining method for high resolution electron microscopy of viruses. Biochimica et biophysica acta 34, 103-1 I0.

Cesari, I. M., Rieber M. \& IMAedA, T. (I969). Localization and properties of enzymes involved with electron transport activity in mycobacteria. Journal of Bacteriology 98, 767-773.

Chen, P. L. (1964). The membrane system of Streptomyces cinnamonensis. American Journal of Botany $\mathbf{5} \mathbf{r}$, I25-132.

Ellar, D. J. \& Freer, J. H. (I969). The isolation and characterization of mesosome material from Micrococcus lysodeikticus. Journal of General Microbiology $\mathbf{5 8}$, vii.

Ghosh, B. K. \& Murray, R. G. E. (I969). Fractionation and characterization of the plasma and mesosome membrane of Listeria monocytogenes. Journal of Bacteriology 97, 426-440.

Glauert, A. M. \& Hopwood, D. A. (1959). A membranous component of the cytoplasm in Streptomyces coelicolor. Journal of Biophysical and Biochemical Cytology 6, 515-5I6.

Glauert, A. M. \& Hopwood, D. A. (I960). The fine structure of Streptomyces coelicolor. I. The cytoplasmic membrane system. Journal of Biophysical and Biochemical Cytology 7, 479-486.

Granboulan, P. \& Leduc, E. H. (1967). Ultrastructural cytochemistry of Bacillus subtilis. Journal of Ultrastructure Research 20, I I I-I 26.

Highton, P. J. (1969). An electron microscopic study of cell growth and mesosomal structure of Bacillus licheniformis. Journal of Ultrastructure Research 26, I30-147.

Highton, P. J. (1970). An electron microscopic study of the structure of mesosomal membranes in Bacillus licheniformis. Journal of Ultrastructure Research 31, 247-259. 
Holt, S. C. \& Leadbetter, E. R. (I969). Comparative ultrastructure of selected aerobic spore-forming bacteria: a freeze-etching study. Bacteriological Reviews 33, 346-378.

Hopwood, D. A. (1967). Genetic analysis and genome structure in Streptomyces coelicolor. Bacteriological Reviews 3I, 373-403.

Hopwood, D. A., Wildermuth, H. \& Palmer, H. M. (1970). Mutants of Streptomyces coelicolor defective in sporulation. Journal of General Microbiology 6r, 397-408.

KutZNER, H. J. \& WAKSMAN, S. A. (I959). Streptomyces coelicolor Müller and Streptomyces violaceoruber Waksman \& Curtis, two distinctly different organisms. Journal of Bacteriology 78, 528-538.

Moor, H. (1964). Die Gefrier-Fixation lebender Zellen und ihre Anwendung in der Elektronenmikroskopie. Zeitschrift für Zellforschung 62, 546-580.

Moore, R. T. \& Chapman, G. B. (I959). Observations of the fine structure and modes of growth of a streptomycete. Journal of Bacteriology 78, 878-885.

Mühlethaler, K., Moor, H. \& Szarkowski, J. W. (1965). The ultrastructure of the chloroplast lamellae. Planta $67,305-323$.

NANNINGA, N. (I968). Structural features of mesosomes (chondrioids) of Bacillus subtilis after freeze-etching. Journal of Cell Biology 39, 25I-263.

Pate, J. L. \& Ordal, E. J. (I967). The fine structure of Chondrococcus columnaris. I. Structure and formation of mesosomes. Journal of Cell Biology 35, I-I3.

Rancourt, M. W. \& Lechevalier, H. A. (1964). Electron microscopic study of the formation of spiny conidia in species of Streptomyces. Canadian Journal of Microbiology ro, 3I I-3I6.

Remsen, C. C. (1968). Fine structure of the mesosome and nucleoid in frozen-etched Bacillus subtilis. Archiv für Mikrobiologie 6r, 40-47.

Ryter, A. (I968). Association of the nucleus and the membrane of bacteria: a morphological study. Bacteriological Reviews 32, 39-54.

Ryter, A. \& LANDMAN, O. E. (1964). Electron microscope study of the relationship between mesosome loss and the stable L state (or protoplast state) in Bacillus subtilis. Journal of Bacteriology 88, 457-467.

StUART, D. C. (1959). Fine structure of the nucleoid and internal membrane systems of Streptomyces. Journal of Bacteriology $78,272-281$.

Wehrli, E., Mühlethaler, K. \& Moor, H. (1970). Membrane structure as seen with a double replica method for freeze-fracturing. Experimental Cell Research 59, 336-339.

WiLDERMUTH, H. (1970a). Surface structure of streptomycete spores as revealed by negative staining and freeze-etching. Journal of Bacteriology 101, 318-322.

Wildermuth, H. (1970 b). Development and organization of the aerial mycelium in Streptomyces coelicolor. Journal of General Microbiology 6o, 43-50.

Wildermuth, H. \& Hopwood, D. A. (1970). Septation during sporulation in Streptomyces coelicolor. Journal of General Microbiology 6o, $5^{\mathrm{I}-59}$. 